\title{
The impact of RFID technologies on inventory accuracy in the apparel retailing: Evidence from the field
}

\author{
Massimo Bertolini*, Eleonora Bottani, Giovanni Romagnoli \\ and Giuseppe Vignali \\ Department of Industrial Engineering, University of Parma, Via G.P. Usberti, Parma, Italy
}

\begin{abstract}
.
In this paper, we assess the level of inventory accuracy that can be reached by adopting radio frequency identification (RFID) technology for inventory count operations in the fashion retailing. Thanks to an in-field implementation, we carried out two series of RFID inventory counts and compared the resulting accuracy level with that obtained exploiting the traditional barcode (BC) technology, so as to highlight the main pros and cons of the RFID adoption.

As a general conclusion, the findings from the experimental campaigns and the analyses carried out suggest that RFID inventory counts are more reliable than BC ones. Moreover, under several circumstances, RFID allows detecting out-of-stock situations that are not evident when using either the BC technology or the inventory data stored in the company' information system. From those findings, a trend of the inventory accuracy as a function of the time required for RFID inventory counts is empirically derived. Such a trend can be exploited in practical cases to estimate the accuracy level achievable with inventory counts depending on the time dedicated to those activities.
\end{abstract}

Keywords: Inventory accuracy, inventory counts, radio frequency identification, barcode, fashion retailing

\section{Introduction}

Inventory is "a quantity of goods or materials in the control of an enterprise and held for a time in a relatively idle or unproductive state, awaiting its intended use or sale" (Love, 1979). Inventory originates from the differences existing between the speed of the supply and demand processes and is required at any level of the supply chain, to provide a buffer between variable, or uncertain, supply- and demand-related activities (Waters, 2003).

Inventory management has obvious impact on the efficiency of a supply chain, since it generates several costs, such as the purchasing cost of items, the order cost, the inventory holding cost and the stock-out (or shortage) cost (Bottani \& Montanari, 2011). Depending on the context, further cost can be associated to product obsolescence and related risk, or to opportunity-cost. Overall, the cost of inventory can be

${ }^{*}$ Corresponding author: Massimo Bertolini, Eng., Ph.D., Associate Professor, Mechanical Industrial Plants, Department of Industrial Engineering, University of Parma, Via G.P. Usberti 181/A 43124 Parma, Italy. Tel.: +390521 905861; Fax: +39 0521 905705; E-mail: massimo.bertolini@unipr.it. 
relevant, reaching, in some cases, $25 \%$ of the product value (Fleisch \& Tellkamp, 2005).

The targeted level of inventory of a product needs to be carefully determined, to reach an optimal balance between cost and service. Indeed, maintaining a high inventory level allows avoiding out-of-stock situations, balancing demand and supply and providing high service level to the customers. Conversely, a lower stock level obviously decreases the cost of inventory holding, although it can involve higher stock-out occurrence or, in general, lower service level provided to the customer (Jacobs \& Chase, 2013). To determine the targeted level of inventory at a given supply chain echelon, however, it is first necessary to gain a precise knowledge of the amount of product available at that echelon, i.e. the "physical" inventory. In this regard, many studies argue that pieces of information concerning the physical inventory of items, retrieved, for instance, from the company's information system, are often wrong or imprecise (Kang \& Gershwin, 2007; Raman et al., 2001; Gruen \& Corsten, 2007). Inventory accuracy is the typical measure adopted to evaluate the level of correctness of information concerning the inventory of an item; it evaluates the discrepancies that exist between the electronic records of the inventory and its physical state (DeHoratius $\&$ Raman, 2008). There are two main categories of inventory inaccuracy. According to the literature, most of the times the physical inventory of the product is overestimated compared to the real amount available, generating a phantom inventory or an understock situation; alternatively, the physical inventory can be underestimated, reflecting a hidden inventory or an overstock situation (Gruen \& Corsten, 2007). This latter circumstance can be due, for instance, to human errors in inventory operations (e.g., incorrect operations of stock checks or inventory counts), thefts, damaged products, or cashier errors (Kang \& Gershwin, 2007).

Both underestimated and overestimated inventory can involve significant consequences to a supply chain player. In the case the inventory is underestimated, the typical consequence is that the supply chain player will experience a relevant cost of holding stocks, and, depending on the kind of product, may incur in obsolescence risk and markdown cost. However, the overstock situation is generally the most critical circumstance; indeed, its direct effect is the out-of-stock occurrence, since the supply chain player fails to issue an order for the product, on the basis of the overestimated inventory (Hardgrave, 2009).

Inventory inaccuracy (and, in particular, overestimated inventory) is therefore one of the direct causes of out-of-stock occurrence. Further out-of-stock causes, as investigated by Corsten and Gruen (2003), include forecasting errors, ordering errors, distribution centre issues, manufacturer issues, transport delays, or shelf replenishment issues. This latter circumstance is particularly frequent in the retail field: in this case, the product is out-of-stock on the store shelf, but it is actually available in the backroom of the retail store, thus suggesting that the shelf replenishment process has not been correctly scheduled. Some studies, such as Thiesse and Buckel (2015), investigate the use of RFID as a tool for improving shelf replenishment processes in stores. The authors sustain that the performance of RFID-based inventory control 
policies is influenced by a variety of design choices, technology characteristics, and external factors.

Although out-of-stock situations may occur at any level of the supply chain, they are particularly crucial for retailers, since the absence of a product at the retail store means a loss of sales and turnover. Estimates of ECR Europe (2003) indicate that, on average, approx. $8.3 \%$ of products are out-of-stock at the retail store. Nonetheless, some circumstances can increase the occurrence of out-of-stock situations. For instance, out-of-stock occurrence is more critical:

- for fast-moving products, i.e. products whose sale velocity is particularly high or whose selling season is very short. Conversely, slow-moving items are less affected by out-of-stock situations;

- for promotional items, since promotions generate a high, less stable and often unpredicted demand of the product (Bottani et al., 2009a). For promotional items, out-of-stock occurrence can reach $10-11 \%$;

- during the week-end, since, in that moment, the number of customers at the retail store can significantly increase.

Fashion items are an example of product whose selling season is very short and that, therefore, suffers particularly from the out-of-stock occurrence. In fact, for fashion items, it is vital to ensure that the product is available at the store shelves as quickly as possible, to avoid sale losses. Moreover, fashion retailers need relevant space to display products of different styles, sizes and colours; consequently, efficiently managing the fashion items at retail stores and ensuring that all styles, sizes and colours are available is a challenging task.

Some recent studies have suggested that both inventory inaccuracy and shelf replenishment issues could be mitigated, or completely avoided, by adopting radio frequency identification (RFID) technology, given its capability to track and trace items at each stage of the supply chain. Therefore, RFID is often suggested as a valuable tool to improve inventory accuracy and decrease out-of-stock occurrence in the fashion field (Bottani et al., 2009a, b; Bertolini et al., 2012).

In this study, we try to contribute to the literature by investigating, thanks to an infield implementation, the level of inventory accuracy that can be reached by adopting RFID technology for inventory count operations of fashion items. The performance of RFID is also compared with that of the traditional barcode (BC) technology, to highlight the main pros and cons of RFID against that technology.

The remainder of the paper is organised as follows. The next section reviews the relevant literature related to the implementation of RFID to improve inventory accuracy in various contexts, with a particular attention to the fashion field. Section 3 describes the experimental apparatus adopted in this study and presents the main results of the experiments carried out. Section 4 concludes and indicates future research steps. 


\section{Literature review}

Numerous studies in literature highlighted the potential of RFID for improving inventory accuracy, primarily in the fast moving consumer goods field. As regards the in-field implementations of RFID, an important study was carried out by Hardgrave et al. (2009a), who monitored 16 Wal-Mart retail stores, for 23 weeks. Starting from the 11th week, eight of those stores were equipped with an RFID-based inventory management system, while the remaining "control" stores continued to adopt the original inventory management system. The authors found that the inventory accuracy of the RFID-equipped stores improved by $13 \%$ compared to the control stores. The same authors (Hardgrave et al., 2006a) also examined the impact of RFID technology to reduce out-of-stock occurrence. By analysing the replenishment process at 24 Wal-Mart retail stores (12 equipped with RFID technology vs. 12 control stores), they found that the out-of-stock occurrence decreased by almost $15 \%$ at the RFID-equipped stores, on average. Looking at the different product categories, Hardgrave et al. (2006b) found that the impact of RFID on out-of-stock occurrence varies significantly depending on the sale velocity of products. In particular, fast-moving products (i.e., products with a sale velocity between 7 and 15 items/day) experienced the highest reduction of out-of-stock, which can reach 62\%. McCartney et al. (2008) investigated, by means of tests, the use of RFID technology for packaging of various kinds of items, including fast moving consumer goods, fashion items and fresh products.

Looking at the analytic models, Rekik et al. (2008) considered inventory inaccuracies stemming from execution problems, and specifically to misplacement errors, occurring, for instance, because of replenishment errors or product misplaced on other shelves by the consumers. They highlighted that significant benefits can be achieved when the retailer adopts RFID technology to eliminate those errors. In another study, the same authors (Rekik et al., 2009) investigated the impact of RFID on the inventory inaccuracy problem induced by thefts. The authors compared different approaches that can be used to manage the store inventory in presence of thefts. In the first approach, the inventory manager is unaware of thefts (and therefore, of the inventory inaccuracy generated), while, in the antithetic situation, a perfect RFIDbased inventory management system is used to control the inventory at the store. The authors analytically determined the savings achievable in inventory management when RFID is deployed. At the same time Fan et al. (2014) studied the use of Radio Frequency Identification (RFID) as a tool for improving shelf replenishment processes in stores. They affirm that the performance of RFID-based inventory control policies is influenced by a variety of design choices, technology characteristics, and external factors. Fan et al. (2014) studied the impact of RFID technology adoption on supply chain decisions with shrinkage and misplacement problems in the Internet of Thing (IoT).

Some studies addressed the implementation of RFID technology in the fashion and apparel supply chain. Among them, Bevilacqua et al. (2015) discussed 
the implementation of a RFID system for the division of the offices and furniture of an Italian company. Loebbecke et al. (2006) analysed the implementation of RFID within a case study company; they found that such technology could significantly improve inventory management in the fashion field. Reynolds et al. (2006) and IDTechEx (2005) suggested the adoption of an RFID-based stock management system to help employees identify the fashion items required by the customer more quickly and accurately. Findings from a pilot project, involving 280 American Apparel fashion stores, confirmed that the in-field implementation of RFID has potential to improve the sales volume of the fashion retail stores by almost 15\% (RFID Journal, December 12th, 2008), thanks to the possibility of precisely monitoring the inventory of items at the fashion retail store. This result is supported also by the pilot implementation by Bertolini et al. (2012), who found that RFID deployment at the retail store can help sales assistant find approx. $14 \%$ of the items requested by the customers and not available on the shelves.

Hardgrave (2009) described an item-level RFID implementation at 4 stores (two RFID-equipped stores vs. two control stores) of the Dillard's supply chain. The 10week study carried out demonstrated that RFID allows improving the accuracy of the inventory data. Specifically, RFID technology introduced a 4\% improvement in the inventory data compared to the full inventory counts performed by the employees. A similar item-level RFID implementation was carried out by Hardgrave et al. (2009b) at Bloomingdale's. Here, the authors investigated inventory accuracy and out-of-stocks, and found that RFID deployment can lead to improve the inventory accuracy up to $27.19 \%$, decreasing the overestimated and underestimated inventory by $6.18 \%$ and $21.01 \%$, respectively. A further RFID pilot implementation was carried out in the J.C. Penney's retail channel, where Miles et al. (2010) examined 5 retail stores ( 2 stores equipped with RFID vs. 3 stores adopting BC technology). After a 15-week analysis, the authors found that the inventory accuracy of the control stores was approx. 7.1\% lower than that of the RFID-equipped stores. Thiesse et al. (2009) carried out an RFID project at Galeria Kaufhof, a large European fashion distributor. They compare the case to a prior trial conducted at the same distributor five years earlier, without RFID technology. The differences between the lessons that the company learned in the two projects illustrate the impact of technological advances and standardization efforts in recent years on the managerial perceptions of RFID business value.

Overall, the review of the literature presented above suggests that RFID looks promising to improve inventory accuracy and related issues (e.g., out-of-stock occurrence), both in the fast moving consumer goods and in the fashion field. In this regard, the main contribution of our study is to investigate the correlation between the level of inventory accuracy enabled by RFID and the corresponding savings in the time required to collect the inventory data. Starting from that correlation, we also highlight the improvements in the accuracy level that can be reached when adopting RFID, compared to the traditional $\mathrm{BC}$ inventory counts. 


\section{Experimental campaign and results}

\subsection{Overview}

Given the aim described above, the experimental campaign carried out in this study was expressively designed to test the performance of the RFID technology in inventory count operations at the retail store, compared with the BC technology. The experimental campaign consisted of two steps. During the first step (preparation), fashion items of a pilot retail store of a main Italian fashion brand were RFID tagged, with a UHF Gen2 paper label, programmed with a unique EPC code. The same operation was carried out on the fashion items available at the upstream distribution centre, in the case they should have been shipped to the retail store.

The second step (inventory counts) consisted in carrying out different types of inventory counts at the retail store, at different times, always when the shop was closed. Inventory counts were carried out both by scanning the BC of the RFID-tagged items and by exploiting the RFID tags, which were read by means of a handheld device. The data collected with the two procedures were then compared, and matched with the inventory data stored in the company's information system. From that comparison, we computed:

1. The reading accuracy, i.e. the percentage of items (or SKUs) read successfully, as a function of the duration of inventory count operations;

2. The degree of alignment between the different inventory data (RFID inventory vs. BC inventory; RFID inventory vs. data on the store information system; BC inventory vs. data on store information system);

3. The out-of-stock level. This latter was computed as the ratio between the number of SKUs whose stock level was found to be null according to the technology adopted, but was expected to be positive according to the real inventory data, and the total amount of SKUs read.

The experimental campaign consisted in two replicates of numerous inventory count operations, carried out both with the BC and the RFID technologies. RFID inventories were performed exploiting three types of handheld RFID readers, whose reading performance were preliminary tested and turned out not to be significantly different. As regards the type of RFID inventory count operations, we carried out:

- Accurate inventory counts. In this case, employees were asked to move the SKUs, the items inside each SKU, the hanging clothes, as well as the folded items placed on the shelves or in the drawers. This procedure is expected to maximise the reading accuracy, allowing the reader to detect also the hidden tags of overlapping clothes;

- Quick inventory counts. This kind of inventory was carried out with significantly less movements of clothes and SKUs; therefore, the resulting accuracy is expected to be lower; 
- Very quick inventory counts. In this case, the employees were asked to carry out the inventory count operations without moving items and SKUs, so as to maximise their productivity.

For each replicate, an additional inventory count was carried out exploiting the $\mathrm{BC}$ technology. Moreover, each replicate was preceded by a manual count of the fashion items available in the store and of the corresponding SKUs, aimed to identify the real number of items and SKUs. These latter, referred to as "expected" values hereinafter, were used as benchmark to assess the correctness of both the inventory count operations and the inventory data stored in the company's information system, which was not realigned after the manual count. The manual count was carried out by an employee that was not subsequently involved in BC or RFID inventory counts, to avoid bias. The store information system and actual inventory was synchronized immediately before (one day) the tests conduction.

\subsection{Analysis of outcomes of the first replication}

The first replication of the experimental campaign consisted, overall, of 25 RFID inventory counts, carried out by 5 store employees in the three main areas of the store; in particular:

- 9 (i.e., 7 accurate and 2 quick) inventory counts were carried out in the underground warehouse of the store;

- 10 (i.e., 5 accurate, 3 quick and 2 very quick) inventory counts were carried out in the store shelves;

- 6 (i.e., 2 accurate, 3 quick and 1 very quick) inventory counts were carried out in the store backroom.

The time required to perform the inventory counts has an obvious direct relationship with the accuracy level reached. Table 1 provides an overview of the time required to carry out the inventory count operations described above.

Once the inventory counts were completed, the resulting data were analysed and compared, to assess the accuracy of the different types of inventory operations. Moreover, the alignment between the inventory levels resulting from the different inventory counts (i.e., BC vs. RFID) was assessed. As regards the inventory accuracy, when considering the aggregated results of the 25 inventory counts, the RFID technology allowed to detect:

- 9,648 items out of 9,698 expected from the manual count (99.5\% accuracy); and

- 2,737 SKUs out of 2,782 expected from the manual count ( $98.2 \%$ accuracy).

By means of the $\mathrm{BC}$ inventory count, instead, we detected:

- 9,752 items out of 9,698 expected from the manual count (100.5\% accuracy);

- 2,781 SKUs out of 2,782 expected from the manual count (99.9\% accuracy). 
Table 1

Duration of inventory count operations - first replication

\begin{tabular}{|c|c|c|c|c|}
\hline Location & $\begin{array}{l}\text { Type of } \\
\text { inventory count }\end{array}$ & Inventory ID & Duration & $\begin{array}{l}\text { Average duration of } \\
\text { the inventory type }\end{array}$ \\
\hline \multirow[t]{9}{*}{ underground warehouse } & accurate & 1 & 00:03:30 & 00:03:42 \\
\hline & & 2 & 00:04:00 & \\
\hline & & 3 & $00: 03: 15$ & \\
\hline & & 4 & 00:03:50 & \\
\hline & & 5 & 00:03:00 & \\
\hline & & 6 & 00:04:00 & \\
\hline & & 7 & 00:04:20 & \\
\hline & quick & 8 & $00: 02: 30$ & 00:02:40 \\
\hline & & 9 & $00: 02: 50$ & \\
\hline \multirow[t]{10}{*}{ store shelves } & accurate & 10 & 00:50:00 & 00:38:00 \\
\hline & & 11 & $00: 42: 00$ & \\
\hline & & 12 & 00:27:00 & \\
\hline & & 13 & $00: 28: 00$ & \\
\hline & & 14 & 00:43:00 & \\
\hline & quick & 15 & 00:16:00 & $00: 22: 20$ \\
\hline & & 16 & $00: 15: 00$ & \\
\hline & & 17 & $00: 36: 00$ & \\
\hline & very quick & 18 & 00:07:00 & 00:07:00 \\
\hline & & 19 & 00:07:00 & \\
\hline \multirow[t]{6}{*}{ backroom } & accurate & 20 & $00: 42: 00$ & 00:50:00 \\
\hline & & 21 & 00:58:00 & \\
\hline & quick & 22 & $00: 13: 00$ & 00:09:00 \\
\hline & & 23 & 00:05:00 & \\
\hline & & 24 & 00:09:00 & \\
\hline & very quick & 25 & 00:02:00 & 00:02:00 \\
\hline
\end{tabular}

With respect to the time required, a BC inventory count requires more than 100 hours to be completed in the three areas of the retail store; conversely, as will be detailed later, the RFID inventory count requires only some hours, in the most unfavourable situation.

From the outcomes above, it is immediately observed that the accuracy, in terms of SKUs detected, is slightly lower for RFID than for BC inventory counts. Conversely, the same performance parameter, measured on the items detected, shows significantly different results. More precisely, the RFID inventory count provides a slight (approx. $0.5 \%$ ) underestimate of the number of items in the retail store, while the $\mathrm{BC}$ inventory count overestimates, of approx. $0.5 \%$, the same value. This is probably due to the fact that BC scanning can generate multiple reads of the same BC label accidentally. Unfortunately, there is no mean to identify multiple readings during the inventory count operations, because the employee is not aware of which items have been read several times. The same happens for the information system of the retail store, which is unable to identify the item subject to multiple reads. Therefore, knowing the exact rate of multiple readings, for instance as a function of the accuracy level, is not feasible with the BC technology. 
As a further result, we assessed the accuracy level (in terms of SKUs and items) as a function of the time required for inventory count operations. To this extent, the RFID inventory counts listed in Table 1 were combined, assuming that the combination, e.g., of two inventory counts, generates an inventory count with the following characteristics: (1) its duration is the sum of the durations of the original inventory count operations; (2) the number of items read is the aggregation of the items read in the original inventory count operations. Given the high number of RFID inventory counts carried out, combining all them is not feasible; therefore, Table 2 lists some of the combinations that can be obtained starting from the set of 25 inventory counts performed in the first replication. For each combination, Table 2 reports the number and type of inventory counts used to generate it, the overall accuracy reached (both at items and SKUs level) and the duration of the inventory count operations. For instance, combination I was obtained by aggregating:

- 7 accurate inventory counts carried out in the underground warehouse (corresponding to the whole amount of accurate inventory counts carried out in this part of the retail store, as can be seen from Table 1);

- 5 accurate inventory counts carried out in the store shelves (corresponding to the whole amount of accurate inventory counts carried out in this part of the retail store); and

- 2 accurate inventory counts carried out in the store backroom (corresponding to the whole amount of accurate inventory counts carried out in this part of the retail store).

The aggregation of the inventory counts listed above leads to an overall duration of the inventory count of 5:15 hours. Combinations are listed in Table 2 in descending order of the total duration they generate. As regards the accuracy level, this latter was assessed by computing the ratio between the number of items (or SKUs) detected by the combination of inventory counts and their expected value. In the case of combination I, the overall accuracy reached is $99.42 \%$ (related to the items) and $98.20 \%$ (related to SKUs).

Figure 1 provides a graphical representation of the outcomes proposed in Table 2.

An expected conclusion from Fig. 1 and Table 2 is that the level of accuracy reached by inventory count operations depends directly on the time dedicated to these activities, i.e. the higher the time dedicated to inventory counts, the higher the accuracy achievable. However, the improvements in accuracy follow a kind of decreasing returns to scale law, meaning that improvements are marginally less effective for increasing values of the total inventory duration. For instance, from Table 2 one can see that, moving from combination VIII to combination VII, the increase in the time required for inventory count operations is $420 \mathrm{~s}$ (approx. 7 minutes), while the corresponding improvement in the accuracy ranges from $4.53 \%$, for items, to $5.24 \%$ for SKUs. Conversely, moving from combination III to combination II, the increase in the time required for inventory count operations is significantly higher $(5,160 \mathrm{~s}$, 


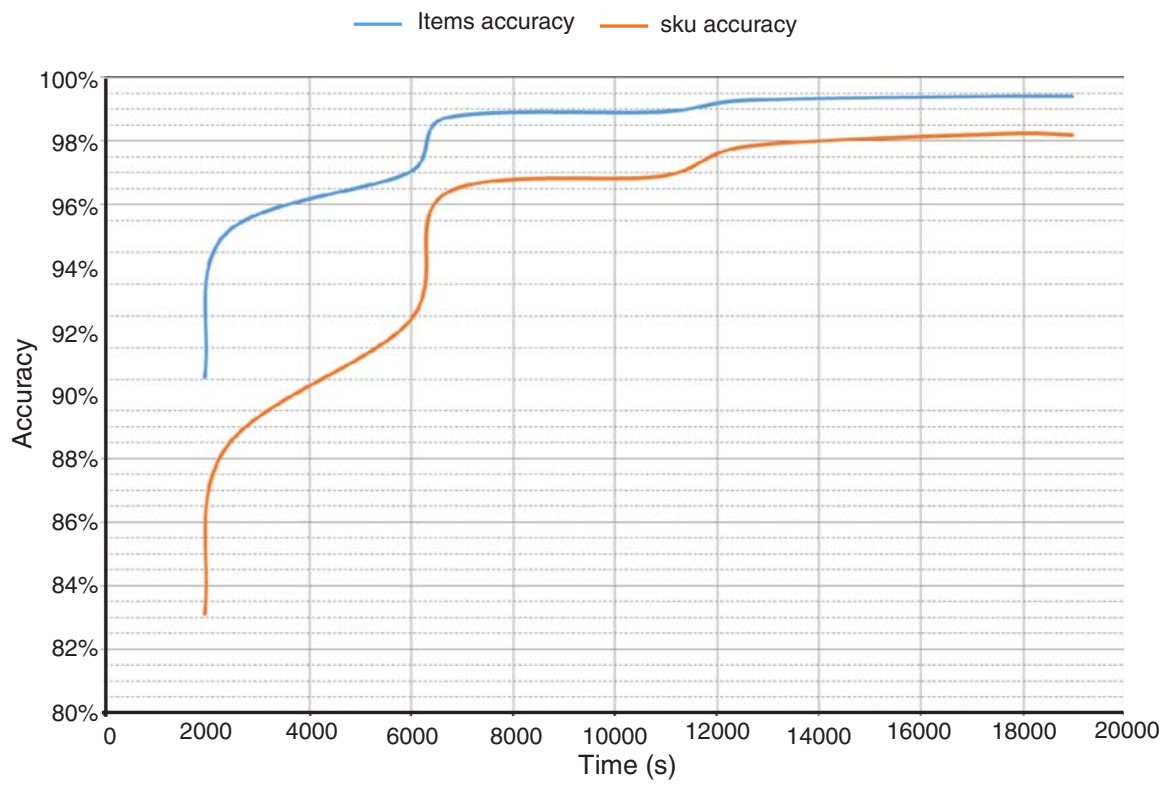

Fig. 1. Inventory accuracy as a function of the duration of inventory count operations - first replication.

approx. 1 hour and 26 minutes), while the improvements in the accuracy level is only $0.13 \%$ for items and $0.40 \%$ for SKUs. The considerations above suggest that, from a practical perspective, it is paramount to preliminary identify a targeted accuracy level the inventory count operations should reach. Data in Table 2 can be useful to identify the most appropriate procedure (i.e., number and type of inventories) to obtain the targeted accuracy level.

From Fig. 1 it is also easy to see that the accuracy as a function of the time required for inventories does not always follow a regular trend. This indicates that, under some circumstances, increasing the time dedicated to inventory count operations does not generate a corresponding improvement in the resulting accuracy level. In turn, this is probably due to the particular combination of inventory counts. As a general rule, it is reasonable that increasing only the number of quick (or very quick) inventory counts generates an increase in the time required for those operations, but does not improve the accuracy level significantly, since quick inventory counts can always be sensitive to reading inaccuracies. Conversely, including at least one accurate inventory count should improve the accuracy of these operations to a more appreciable extent.

As regards the comparison between the results of the BC and RFID inventory counts with the inventory data available in the company's information system, we found the results proposed in Table 3 .

Columns 2 to 4 in Table 4 were obtained by computing, for each SKU, the difference between the inventory level resulting when exploiting the first system and the 


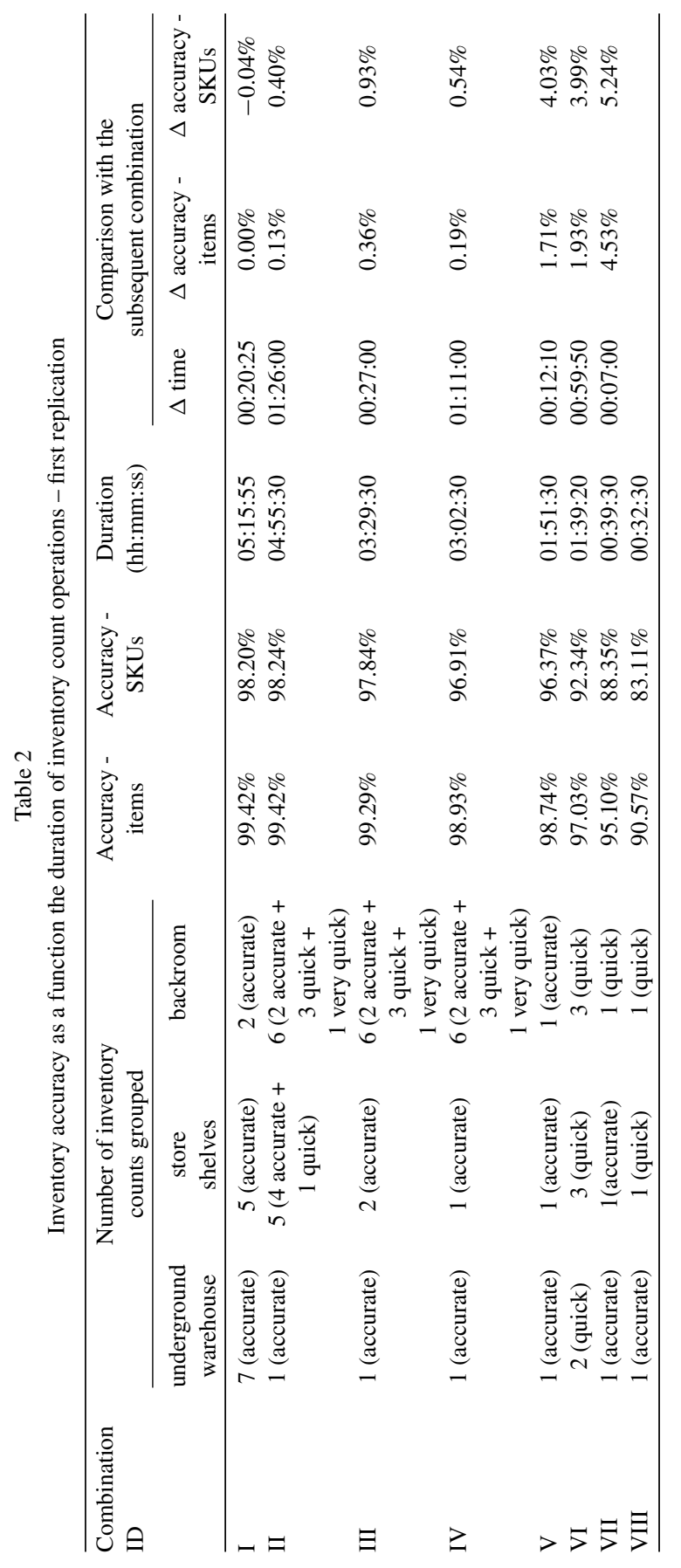


Table 3

Comparison between the inventory data collected by inventory counts and those available in the company's information system - first replication

\begin{tabular}{lccc}
\hline & $\begin{array}{c}\text { Information } \\
\text { system vs. BC } \\
\text { inventory count }\end{array}$ & $\begin{array}{c}\text { Information } \\
\text { system vs. RFID } \\
\text { inventory count }\end{array}$ & $\begin{array}{c}\text { BC inventory } \\
\text { count vs. RFID } \\
\text { inventory count }\end{array}$ \\
\hline $\begin{array}{l}\text { Correspondence of inventory data } \\
\text { The first system overestimates the inventory } \\
\text { compared to the second one }\end{array}$ & $\begin{array}{c}92.18 \% \\
5.44 \%\end{array}$ & $\begin{array}{c}90.87 \% \\
7.25 \%\end{array}$ & $3.16 \%$ \\
$\begin{array}{l}\text { The first system underestimates the } \\
\text { inventory compared to the second one }\end{array}$ & $2.38 \%$ & $1.88 \%$ & $0.82 \%$ \\
$\begin{array}{l}\text { Out-of-stock situations neglected by the first } \\
\text { system but detected by the second one }\end{array}$ & $1.10 \%$ & $1.14 \%$ & $0.14 \%$ \\
\hline
\end{tabular}

Table 4

Details of the difference between the inventory data - first replication

\begin{tabular}{lccccr}
\hline $\begin{array}{l}\text { Amount of the } \\
\text { difference } \\
\text { Information } \\
\text { system vs. BC } \\
\text { inventory count }\end{array}$ & $\%$ SKU & $\begin{array}{c}\text { Amount of the } \\
\text { difference } \\
\text { Information } \\
\text { system vs. RFID } \\
\text { inventory count }\end{array}$ & SKU & $\begin{array}{c}\text { Amount of the } \\
\text { difference BC } \\
\text { inventory } \\
\text { count vs. RFID } \\
\text { inventory count }\end{array}$ & $\%$ SKU \\
\hline-3 & $0.04 \%$ & -3 & $0.00 \%$ & -3 & $0.00 \%$ \\
-2 & $0.14 \%$ & -2 & $0.07 \%$ & -2 & $0.07 \%$ \\
-1 & $2.20 \%$ & -1 & $1.81 \%$ & -1 & $0.75 \%$ \\
0 & $92.18 \%$ & 0 & $90.87 \%$ & 0 & $96.02 \%$ \\
1 & $4.72 \%$ & 1 & $6.43 \%$ & 1 & $2.88 \%$ \\
2 & $0.53 \%$ & 2 & $0.57 \%$ & 2 & $0.18 \%$ \\
3 & $0.14 \%$ & 3 & $0.18 \%$ & 3 & $0.11 \%$ \\
\hline
\end{tabular}

second one. For instance, column "Information system vs. BC inventory count" was obtained as the difference between the inventory registered in the company's information system and that detected by means of the BC inventory count, in terms of items in each SKU. The first row of the table (i.e., "correspondence of inventory data") reports the percentage of SKUs for which the inventory data recorded in the two systems are aligned. For instance, in the case of information system vs. BC inventory counts, we found that the inventory data (related to items) provided by the two systems do not differ for $92.18 \%$ of the SKUs examined. The second row reports the percentage of SKUs for which the first system overestimates the inventory data compared to the second one. In the case of information system vs. BC inventory counts, we found that, for approx. 5.44\% of the SKUs, the inventory data available in the company's information system are overestimated compared to those detected by the BC inventory count. Similar considerations hold for the third row of Table 4, where we report the percentage of SKUs for which the first system underestimates the inventory data 
compared to the second one. Looking again at the case of information system vs. $\mathrm{BC}$ inventory counts, we found that, for approx. $2.38 \%$ of SKUs, the inventory data available in the company's information system are underestimated compared to those detected by the BC inventory count. Finally, the last row of the Table reports the percentage of SKUs for which the second system detects an out-of-stock situation, while the first one does not, meaning that, according to this latter, the available inventory is greater than zero. Looking at those latter values, we found that:

- Approx. 1.1\% of the SKUs that were recorded as available in the company's information system, resulted as out-of-stock in the BC inventory count;

- Approx. $1.14 \%$ of the SKUs that were recorded as available in the company's information system, resulted as out-of-stock in the RFID inventory count;

- Approx. 0.14\% of the SKUs that were recorded as available in the BC inventory count, resulted as out-of-stock in the RFID inventory count.

The above data indicate that the company's information system probably suffered from some (pre-existing) inventory inaccuracy errors, which, in turn, could be due to the limited realignments made with the real inventory data. In the case of inventory inaccuracy errors, both the $\mathrm{BC}$ and the RFID inventory counts can be useful to realign the inventory data and eventually avoid the occurrence of out-of-stock situations. In this regard, the above data also indicate that the RFID inventory counts are slightly more reliable (approx. $0.03 \%$ ) than the BC ones in identifying inventory inaccuracies in the company's information system.

On the basis of the outcomes above, some preliminary conclusions can be drawn. First, the RFID inventory data and the BC ones coincide for $96.02 \%$ of the SKUs considered, and, therefore, it is reasonable to hypothesise that those data reflect the real inventory available in the store. Conversely, the correspondence between the inventory data recorded in the information system and those resulting from the BC inventory count is lower $(92.18 \%)$, as well as the correspondence between the inventory data recorded in the information system and those resulting from the RFID inventory count (90.87\%). This indicates, once again, that the information system was probably not aligned with the real inventory of the store.

Second, the use of RFID inventory counts allowed also identifying some situations where the inventory level resulting from the BC inventory count was actually overestimated (3.16\% of SKUs). The overestimate of stocks, as mentioned, is a serious issue of inventory management, since it has potential to generate out-of-stock situations; those phenomena could be reduced when RFID technology is adopted. Finally, the use of RFID for inventory counts allows identifying some out-of-stock situations that were not evident with either the BC inventory $(0.14 \%)$ or data stored in the company's information system $(1.14 \%)$. Therefore, RFID has potentials to reduce the cost related to out-of-stock situations, by improving items availability on the store shelves and thus enhancing the turnover of the retail store. 
The data reported in Table 3 can be further detailed, by assessing the number of SKUs for which a slight difference (from -3 items to 3 items) was observed when using different inventory data. These details are reported in Table 4.

\subsection{Analysis of outcomes of the second replication}

The second replication included, overall, 10 RFID inventory counts, carried out by 5 employees of the retail store. Since the procedure followed for the second replication is the same as that described in the first one, we do not present the detailed outcomes of each inventory carried out during this replication, for brevity. Rather, we limit the presentation of the results to the number of inventory counts and their average duration. In this respect, the second replication included:

- 2 (accurate) inventory counts, with an average duration of 33:30 minutes, carried out in the underground warehouse of the store;

- 4 inventory counts (i.e., 2 accurate, with an average duration of 35:30 minutes, and 2 quick, with an average duration of 15:30 minutes) carried out in the store shelves;

- 4 inventory counts (i.e., 2 accurate, with an average duration of 38:00 minutes, and 2 quick, with an average duration of 17:00 minutes) carried out in the store backroom.

As can be seen from the description above, in the second replication very quick inventory counts were no longer carried out, because of the scarce accuracy of the outcomes observed in the first replication.

As regards the accuracy, the data collected during the second replication confirm that, in general, RFID inventory counts are sufficiently reliable. Indeed, when considering the aggregated results of the 10 inventory counts, the RFID technology allowed to detect:

- 9,657 items out of 9,721 expected from the manual count (99.3\% accuracy); and

- 2,868 SKUs out of 2,870 expected from the manual count (99.9\% accuracy).

By means of BC inventory counts, instead, we detected:

- 9,753 items out of 9,721 expected from the manual count (100.3\% accuracy); and

- 2,862 SKUs out of 2,870 expected from the manual count (99.7\% accuracy).

As observed in the first replication, the time spent for the inventory counts has an obvious direct relationship with the accuracy level reached by the inventory operations. Indeed, in both replications, we found a very similar trend of the accuracy as a function of the time dedicated to the inventory count, as shown in Table 5 and Fig. 2.

From the data in Table 5, it is immediate to see that the duration of inventory counts in the second replication was lower than that of the first replication; accordingly, the accuracy level reached is lower too. However, apart from this preliminary remark, the 


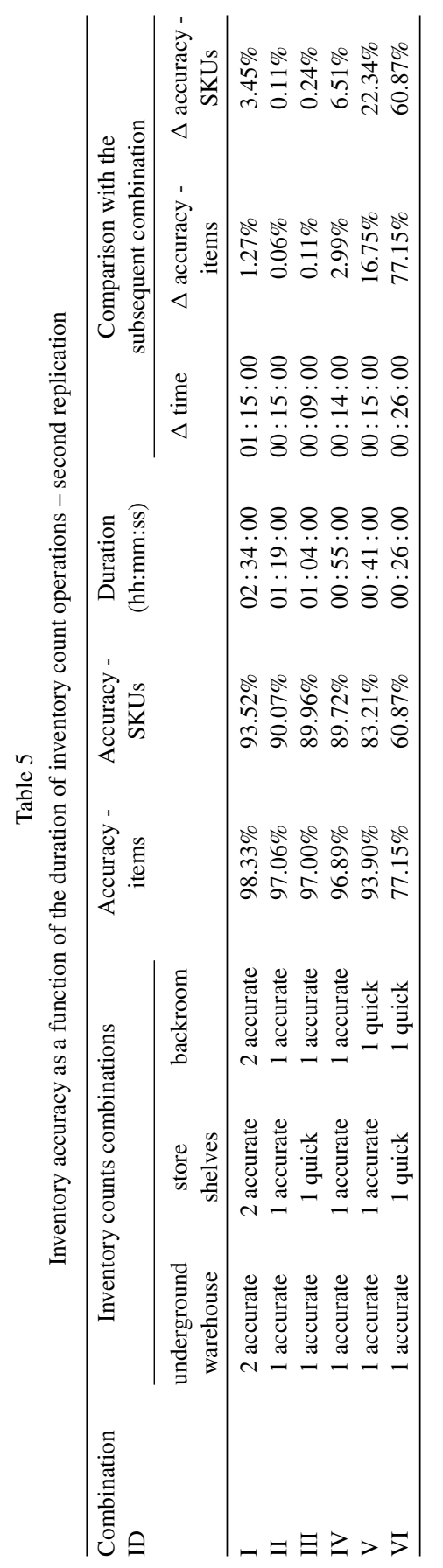




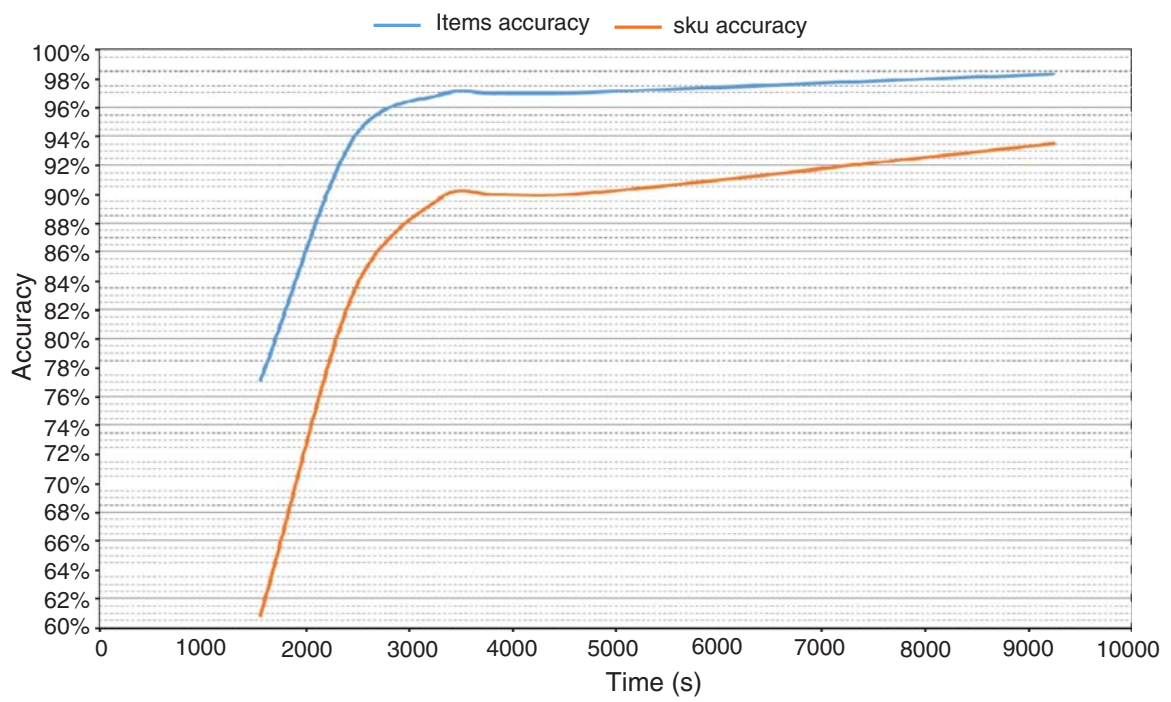

Fig. 2. Inventory accuracy as a function of the duration of inventory count operations - second replication.

two replicates are very similar and both follow the decreasing returns to scale law, i.e. improvements in the accuracy level are marginally less appreciable for increasing values of the inventory duration. For instance, moving from combination VI to combination $\mathrm{V}$, the time required for inventory counts increased by approx. $900 \mathrm{~s}$, while the increase in the accuracy level accounts for more than $16 \%$. Conversely, moving from combination II to combination I, the increase in the time required for inventory counts is significantly more relevant (approx. 4,500 s), while the improvements in the accuracy level are not so appreciable (less than $1.3 \%$ ). From a practical viewpoint, these outcomes confirm that it is first necessary to identify a targeted accuracy level for inventory count operations, and then to define the most appropriate combination of inventories that allows reaching the targeted accuracy.

As regards the correctness of the inventory data (obtained either by means of BC or RFID) compared with those available on the company's information system, we found the results proposed in Table 6 .

From the numerical outcomes in Table 6, it is immediate to see that the inventory data stored on the company's information system and those retrieved by means of BC inventory counts are in agreement for $91.47 \%$ of the SKUs examined. At the same time, however, the company's information system overestimates the inventory detected by means of BC scanning for $5.92 \%$ of the SKUs and underestimates it for $2.61 \%$ of the SKUs. As regards the out-of-stock situations, we found that $1.41 \%$ of the SKUs that were recorded as available on the company's information system were actually out-of-stock according to the BC inventory count. That percentage accounts for $1.27 \%$ when comparing the inventory data in the company's information system 
Table 6

Comparison between the inventory data collected by inventory counts and those available in the company's information system - second replication

\begin{tabular}{lccc}
\hline & $\begin{array}{c}\text { Information } \\
\text { system vs. BC } \\
\text { inventory count }\end{array}$ & $\begin{array}{c}\text { Information } \\
\text { system vs. RFID } \\
\text { inventory count }\end{array}$ & $\begin{array}{c}\text { BC inventory } \\
\text { count vs. RFID } \\
\text { inventory count }\end{array}$ \\
\hline $\begin{array}{l}\text { Correspondence of inventory data } \\
\text { The first system overestimates the inventory } \\
\text { compared to the second one }\end{array}$ & $\begin{array}{c}91.47 \% \\
5.92 \%\end{array}$ & $\begin{array}{c}89.61 \% \\
8.26 \%\end{array}$ & $\begin{array}{c}93.71 \% \\
4.64 \%\end{array}$ \\
$\begin{array}{l}\text { The first system underestimates the } \\
\text { inventory compared to the second one }\end{array}$ & $2.61 \%$ & $1.65 \%$ \\
$\begin{array}{l}\text { Out-of-stock situations neglected by the first } \\
\text { system but detected by the second one }\end{array}$ & $1.41 \%$ & $1.27 \%$ & $0.24 \%$ \\
\hline
\end{tabular}

Table 7

Details of the difference between the inventory data - second replication

\begin{tabular}{lccccr}
\hline $\begin{array}{l}\text { Amount of the } \\
\text { difference } \\
\text { Information } \\
\text { system vs. BC } \\
\text { inventory count }\end{array}$ & SKU & $\begin{array}{c}\text { Amount of the } \\
\text { difference } \\
\text { Information } \\
\text { system vs. RFID } \\
\text { inventory count }\end{array}$ & SKU & $\begin{array}{c}\text { Amount of the } \\
\text { difference BC } \\
\text { inventory } \\
\text { count vs. RFID } \\
\text { inventory count }\end{array}$ & $\%$ SKU \\
\hline-3 & $0.03 \%$ & -3 & $0.28 \%$ & -3 & $0.17 \%$ \\
-2 & $0.14 \%$ & -2 & $0.58 \%$ & -2 & $0.21 \%$ \\
-1 & $2.44 \%$ & -1 & $7.29 \%$ & -1 & $4.23 \%$ \\
0 & $91.47 \%$ & 0 & $89.61 \%$ & 0 & $93.70 \%$ \\
1 & $5.33 \%$ & 1 & $2.06 \%$ & 1 & $1.51 \%$ \\
2 & $0.38 \%$ & 2 & $0.07 \%$ & 2 & $0.03 \%$ \\
3 & $0.07 \%$ & 3 & $0.00 \%$ & 3 & $0.03 \%$ \\
\hline
\end{tabular}

with those resulting from the RFID inventory count. Moreover, for $0.24 \%$ of the SKUs, the RFID inventory count allowed to detect an out-of-stock situation that the BC inventory count did not detected.

Those outcomes support our preliminary conclusion about the pre-existence of inventory inaccuracies in the company's information system. Moreover, it is also confirmed that the accuracy of RFID inventory counts is slightly higher than that of the $\mathrm{BC}$ inventory counts. RFID inventory counts, at the same time, requires significantly less time to be carried out, compared to the $\mathrm{BC}$ inventory counts.

The data reported in Table 7 were elaborated further, by assessing the number of SKUs for which a slight difference (from -3 items to 3 items) was observed when using different inventory methods.

\section{Discussion and conclusions}

In this study, we have analysed the level of inventory accuracy achievable when adopting RFID technology for inventory count operations in fashion retailing. 
Exploiting an in-field implementation of RFID technology in a pilot retail store of fashion items, we carried out an experimental campaign, consisting of two series of 25 and 10 RFID inventory counts, respectively. For each inventory count, we computed the time required to complete it, as well as the level of inventory accuracy reached. This latter was compared with that obtained by means of a traditional BC inventory count, and with that resulting when using the inventory data stored in the company's information system.

From the experimental campaign and the analysis of the inventory data, the following main conclusions can be drawn:

- A first consideration is that, when assessing the inventory accuracy in terms of SKUs detected, RFID and BC inventory counts provide almost identical results;

- Looking, instead, at the inventory accuracy in terms of the items detected, RFID inventory counts are, in general, more reliable than BC ones. More precisely, we found that RFID inventory counts tend to underestimate (slightly) the real inventory, while $\mathrm{BC}$ ones tend to overestimate it, due to the fact that $\mathrm{BC}$ scanning can accidentally generate multiple reads of the same label. We have already remarked that there is no mean to precisely identify items that are read several times during inventory count operations. Nonetheless, overestimate of the inventory is a more serious problem than its underestimate, since it may cause out-of-stock situations;

- RFID inventory counts are also more effective than BC ones, as well as of the company's information system, in detecting potential out-of-stock situations. Indeed, we found that, for a limited percentage of SKUs, both the BC inventory count and the inventory data stored in the company's information system indicated the availability of stock, while the RFID inventory count detected an out-of-stock situation.

- The considerations above confirm that RFID looks promising to improve inventory accuracy and related issues, such as the out-of-stock occurrence, in the fashion retailing.

Obviously, the level of inventory accuracy has a direct relationship with the time required to carry out the inventory count operations. In this regard, in this study we considered three different types of RFID inventory counts, namely accurate, quick and very quick. We found that very quick inventory counts, carried out by the employees without moving the items inside the SKUs, can reach a very limited accuracy, although maximising the employee productivity. An opposite result was found for accurate inventory counts: in this case, the duration is significantly higher, but the inventory accuracy increases significantly.

On the basis of this consideration, thanks to the experimental data retrieved in this work, we have tried to model the trend of the accuracy in inventory operations as a function of the time spent for inventory counts (in the case RFID technology is adopted). The trend of the RFID inventory accuracy as a function of time is shown 
(a) — Items accuracy - -. Interpolation

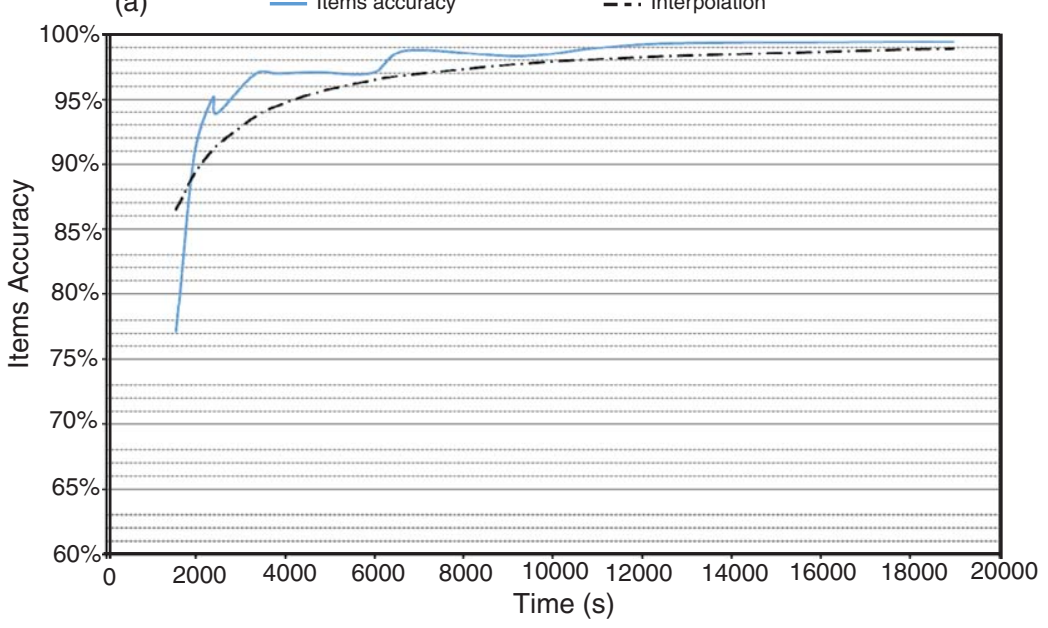

(b) — sku accuracy _... Interpolation

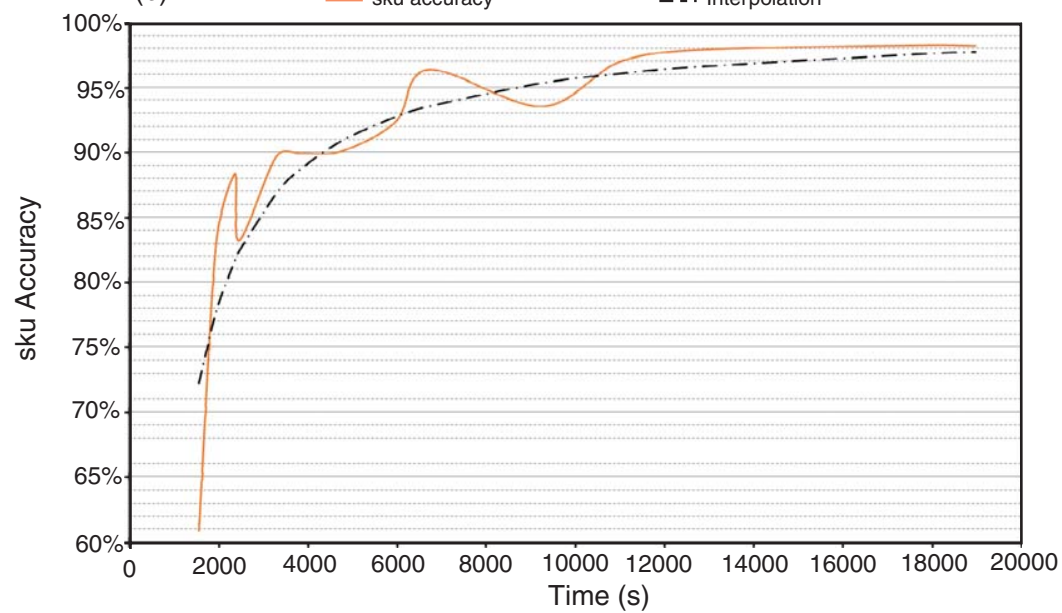

Fig. 3. Trend of the items (a) and SKU (b) accuracy of RFID inventory counts - combination of data from the two replications.

in Fig. 3 for items (a) and SKUs (b) respectively. Obviously, since we exploited the experimental data of the inventory counts, neither the items accuracy nor the SKUs accuracy shows a perfectly regular trend in time; therefore, an interpolation was generated to fit the experimental data (dashed line in both figures). The interpolation shows a logarithmic trend of the inventory accuracy in time, both for items and SKUs. This confirms that the inventory accuracy follows a decreasing return to scale law: it increases significantly when moving, for instance, from 2000 to $4000 \mathrm{~s}$, while its decrease is significantly lower when moving from 12000 to $14000 \mathrm{~s}$. 
The trend of inventory accuracy as a function of the time is the most relevant contribution of this study to the existing literature. Indeed, modelling the trend of inventory accuracy in time could be useful, in real cases, to estimate the time required for a RFID inventory count to reach a targeted level of accuracy. That trend could also be exploited to identify the "optimal" accuracy of inventory count operations, as a compromise solution between the errors made by the system and the time required for inventory counts.

The exact result of this study, in terms of the specific trend of the inventory accuracy as a function of the time devoted to inventory count operations, cannot be generalised, obviously. Indeed, this result has been obtained targeting inventory count operations in the fashion industry and a specific retail store of fashion items. Nonetheless, the general idea behind the results proposed could be generalized and, probably, could hold for several different contexts. Further research activities could be oriented to repeat the analysis carried out in this paper in different industry fields, to gain further insights about the relationships between the inventory accuracy and the time required for inventory count operations.

\section{References}

Bertolini, M., Bottani, E., Ferretti, G., Rizzi, A., \& Volpi, A. (2012). Experimental evaluation of business impacts of RFID in apparel and retail supply chain. International Journal of RF Technologies: Research and Applications, 3(4), 257-282.

Bevilacqua, M., Ciarapica, F.E., Crosta, A., Mazzuto, G., \& Paciarotti, C. (2015). Implementation of a RFID system in a furniture industry involved in the fashion sector: A case study. International Journal of RF Technologies: Research and Applications, 6(2-3), 99-119.

Bottani, E., \& Montanari, R. (2011). Design and performance evaluation of supply networks: A simulation study. International Journal Business Performance and Supply Chain Modelling, 3(3), 226-269.

Bottani, E., Montanari, R., \& Rizzi, A. (2009a). The impact of RFID technology and EPC system on stock-out of promotional items. International Journal of RF Technologies: Research and Applications, 1(1), 6-22.

Bottani, E., Bertolini, M., Montanari, R., \& Volpi, A. (2009b). RFID-enabled Business Intelligence Modules for supply chain optimization. International Journal of RF Technologies: Research and Applications, 1(4), 253-278.

Corsten, D., \& Gruen, T. (2003). Desperately seeking shelf availability: An examination of the extent, the causes, and the efforts to address retail out-of-stocks. International Journal of Retail \& Distribution Management, 31(11-12), 605-617.

DeHoratius, N., \& Raman, A. (2008). Inventory record inaccuracy: An empirical analysis. Management Science, 54(4), 627-641. DOI:10.1287/mnsc.1070.0789

ECR Europe (2003). Optimal shelf availability: Increasing shopper satisfaction at the moment of truth. Retrieved April 2009 from http://www.ecr-institute.org/publications/best-practices/optimalshelfavailability

Fan, T., Tao, F., Deng, S., \& Li, S. (2015). Impact of RFID technology on supply chain decisions with inventory inaccuracies. International Journal of Production Economics, 159, 117-125.

Fan, T.-J., Chang, X.-Y., Gu, C.-H., Yi, J.-J., \& Deng, S. (2014). Benefits of RFID technology for reducing inventory shrinkage. International Journal of Production Economics, 147, 659-665.

Fleisch, E., \& Tellkamp, C. (2005). Inventory inaccuracy and supply chain performance: A simulation study of a retail supply chain. International Journal of Production Economics, 95(3), 373-385. 
Gruen, T.W., \& Corsten, D. (2007). A Comprehensive Guide to Retail Out-of-Stock Reduction in the Fast-Moving Consumer Goods Industry. Retrieved June 2009 from http://www.gmabrands.com/ publications/docs/2007/OOS_fullreport.pdf

Hardgrave, B. (2009). Item level RFID for apparel: The Dillard's RFID initiative. Working paper no.ITRIWP146-0409 of the University of Arkansas, Information Technology Research Institute. Retrieved June 2011 from http://itri.uark.edu

Hardgrave, B.C., Aloysius, J., \& Goyal, S. (2009a). Does RFID improve inventory accuracy? A preliminary analysis. International Journal of RF Technologies: Research and Applications, 1(1), 44-56.

Hardgrave, B.C., Miles, R.S., \& Mitchell, Y. (2009b). Item level RFID for apparel: The Bloomingdale's RFID initiative. Working paper no.ITRI-WP147-0809 of the University of Arkansas, Information Technology Research Institute. Retrieved June 2013 from http://itri.uark.edu

Hardgrave, B.C., Waller, M., \& Miller, R. (2006a). Does RFID Reduce Out of Stocks? A Preliminary Analysis. Working paper no.ITRI-WP058-1105 of the University of Arkansas, Information Technology Research Institute. Retrieved December 2007 from http://itri.uark.edu

Hardgrave, B.C., Waller, M., \& Miller, R. (2006b). RFID's impact on out of stocks: A sales velocity analysis. Working paper no.ITRI-WP068-0606 of the University of Arkansas, Information Technology Research Institute. Retrieved December 2007 from http://itri.uark.edu

IDTechEx (2005). RFID progress at Wal-Mart. Retrieved March 2012 from www.idtechex.com/ products/en/articles/00000161.asp

Jacobs, F.R., \& Chase, R.B. (2013). Operations and Supply Chain Management: The Core (3rd ed.). McGraw-Hill Higher Education. ISBN 0073525235

Kang, Y., \& Gershwin, S.B. (2007). Information inaccuracy in inventory systems: Stock loss and stockout. IIE Transactions, 37(9), 843-859.

Loebbecke, C., Palmer, J., \& Huyskens, C. (2006). RFID's potential in the fashion industry a case analysis. Proceedings of the 19th Bled e-Conference e-Values. Faculty of Organizational Sciences, University of Maribor, Bled, Slovenia, June 5-7, 2006. Retrieved January 2009 from http://www. mtm.uni-koeln.de/team-loebbecke-publications-conf-proceedings/Conf-096-2006-RFIDs-Potentialin-the-Fashion-Industry-a-Case-Analysis.pdf

Love, S. (1979). Inventory control. McGraw-Hill. ISBN: 9780070387829.

McCartney, M., Singh, J., \& Clarke, R. (2008). RFID research and testing for packages of apparel, consumer goods and fresh produce in the retail distribution environment. Packaging Technology and Science, 21, 91-102. DOI: $10.1002 /$ pts.782

Miles, R.S., Mitchell, Y., \& Hardgrave, B.C. (2010). Item-level RFID for apparel/footwear: The JCPenney RFID initiative. Working paper no.ITRI-WP151-0410 of the University of Arkansas, Information Technology Research Institute. Retrieved March 2012 from http://itri.uark.edu

Raman, A., DeHoratius, N., \& Ton, Z. (2001). Execution: The missing link in retail operations. California Management Review, 43(3), 136-152.

Rekik, Y., Sahin, E., \& Dallery, Y. (2008). Analysis of the impact of the RFID technology on reducing product misplacement errors at retail stores. International Journal of Production Economics, 112(2), 264-278.

Rekik, Y., Sahin, E., \& Dallery, Y. (2009). Inventory inaccuracy in retail stores due to theft: An analysis of the benefits of RFID. International Journal of Production Economics, 118(1), 189-198.

Reynolds, K.E., Folse, J.A.G., \& Jones, M.A. (2006). Search regret: Antecedents and consequences. Journal of Retailing, 82(4), 339-348.

RFID Journal (2008). American Apparel expands RFID to additional stores. Retrieved March 2012 from http://www.rfidjournal.com/article/articleview/4510

Thiesse, F., Al-Kassab, J., \& Fleisch, E. (2009). Understanding the value of integrated RFID systems: A case study from apparel retail. European Journal of Information Systems, 18(6), 592-614. DOI: $10.1057 /$ jis. 2009.33 
Thiesse, F., \& Buckel, T. (2015). A comparison of RFID-based shelf replenishment policies in retail stores under suboptimal read rates. International Journal of Production Economics, 159, 126-136.

Waters, D. (2003). Logistics: An introduction to Supply Chain Management. Palgrave MacMillan, New York. ISBN 0333963695 